K.M. Vasyliv

\title{
A MATHEMATICAL MODEL OF THERMAL POWER PLANTS SMOKE EXHAUSTERS INDUCTION MOTORS SYSTEM OPERATION MODES
}

\begin{abstract}
Purpose. Development of a model-software complex (MSC) for computer analysis of modes of the system of induction motors (IM) of smoke exhausters of thermal power plant (TPP), the basic elements of which are mathematical models and corresponding software written in the programming language FORTRAN. Methodology. Mathematical model serves as a system of differential equations of electrical and mechanical condition. The equation of electric state is written in phase coordinates based on Kirchhoff's laws, and mechanical condition described by the d'Alembert equation. Mathematical model focuses on explicit numerical integration methods. Scientific novelty. The equation of state of electrical connections takes into account the mutual electromagnetic circuits for transformer of own needs (TON) and induction motors and interdependence (in all possible combinations) between: TON (from which motors powered) and each of the two IM and blood pressure between themselves. The complex allows to simulate electromagnetic and electromechanical processes in transitional and steady, symmetric and asymmetric modes including modes of self-induction motors. Results. Complex is used for computer analysis of electromagnetic and electromechanical processes and established the basic laws of motion modes of starting, stopping and self-start of IM of smoke exhausters of the TPP unit. Practical value. The complex is suitable for computer analysis of modes of other similar units of own needs of thermal power plants. References 9, figures 12.
\end{abstract}

Key words: mathematic model, numerical methods, thermal power plant, induction motors.

Разработана математическая модель электротехнического комплекса: «Электрическая сеть - трансформатор - два асинхронных двигателя" в фазных координатах, ориентированную на явные методы численного интегрирования системы дифференциальных уравнений. На базе математической модели создан программный комплекс и произведено исследование электромагнитных и электромеханических процессов и установлено основные закономерности их протекания в режимах пуска, останова и самозапуска асинхронных двигателей дымососов энергоблока тепловой электрической станции. Библ. 9, рис. 12.

Ключевые слова: математическая модель, численные методы, тепловая электростанция, асинхронные двигатели.

Problem definition. Powerful thermal power plants (TPP) are used as one base structures of modern power system of Ukraine. At least a half of electricity generated in Ukraine is accounted for the power station. It should be noted that thermal power plants generate huge electricity percent in other advanced industrially developed countries and Europe, and the world.

The reliability and efficiency of thermal power plants in general, scrap, and their power blocks, in particular, essentially depends on the stability and reliability of operation, and the resulting performance of large-keel bones electricity consumers, including powerful industries, transport systems and other consumers.

Reliability of large thermal power plants is determined by reliable operation of turbogenerators that generate electrical energy directly and therefore considered the most important units of power blocks of TPP. Turbogenerators operation, in its turn, is determined by units such important units as steam turbines and boilers, which belong to the group of key ones.

Modern TPP units are highly advanced and automated. This means that the operation of the basic units of TPP provides large number number of other units that belong to auxiliary. These include mechanisms for transportation and fuel supply (if the TPP is working on coal), a number of different pumps (nutritious condensate, circulation) and blowing devices and smoke exhausters and so on. All these auxiliary units called units of own needs $(\mathrm{ON})$, which divided into important and nonimportant. Refusal to operation of important ON units leads to a violation of basic technological cycle of production of electrical energy and even disable of main units: turbogenerators, steam turbines, boilers, and refusal of non-important has no such a critical influence.

In modern thermal power plants almost all their needs mechanisms of $\mathrm{ON}$ driven by short-circuit induction motors (IM) power of which reaches several MW. Induction motors are used to drive and smoke exhausters, whose operation is critical for the unit. After the rejection in the other two smoke exhausters leads to lower unit productivity by $30-40 \%$ and the rejection of two smoke exhausters - emergency stop to the boiler and consequently disable the unit.

ON units in its purpose serves as a «hand» that provides the service personnel unit in the set mode (start and stop the unit, increasing and decreasing issuing power to the grid, and so on). Virtually supports the following modes of power control of electric motors (EM) own power needs. Therefore, to correct and efficient operation of the TPP issue analysis modes of electric motors of own needs is crucial. In this context, critical analysis is correct mode start-up and running-out of electric motors, increase and decrease the frequency of rotation to adjust the performance of the mechanisms set in motion these motors, as well as the self and switch to back-and-purpose and urgent supply.

Analysis of the results of scientific publications and case studies. The issue analysis modes of electric motors mechanisms of own needs of power plants is given quite a large number of scientific papers. Preferably, these works are based on the classical theory of electrical machines and aimed at studying the characteristics and regularities of electromagnetic and electromechanical processes that occur in systems of 
electric motors ON main types of power plants (thermal and nuclear). In terms of the practice of power units of power plants is urgent analysis of electromagnetic and electromechanical processes of electric own needs without exception in all modes of operation: starting, nominal mode and learning processes and self freewheel. These questions serve as the subject of analysis modes of their electric needs sources [1, 3-5, 7, 9]. For example, in [1] describes the overall structure, basic mechanisms, motors, electrical circuits OP thermal power plants. Considered electric modes of their own needs, the control circuit relay protection and automation of electric motors and network elements 6.3 and $0.4 \mathrm{kV}$. The question of improving the reliability of the electric power station and ON prospects of controlled electric AC. The analysis of the characteristics of damage $\mathrm{ON}$ and the ways to prevent them [3] the general characteristics of units own needs of power plants (PP), the processes of starting and runningout of electric motors own needs. Self-described impact on technological operation unit is described. The above general requirements for electrical circuits and $\mathrm{ON}$ are the most common ones. A simplified calculation of self electric motors own needs. In [4] the system of own needs of different types of plants, their characteristics are mechanisms as well as the analysis of the mechanisms of self motors own needs. The question of choice of transformers, DC installations and electrical circuits personal needs.

Fundamental analysis of modes of asynchronous and synchronous motors is made in [7]. Here are some key features of loading, considerable attention is highlighted issues of electric heating. The problems of asymmetric modes of the motors and jacks are considered. Sufficiently and thoroughly describes the self-starter and electric motors. The problem of self motor conditions and results of experimental studies of these regimes is considered. The question of single and group run out of electric AC motors. All these questions are important for practical operation of electric motors needs its own power station.

Relevance of the research. The presence of scientific works which made analysis modes of electric motors mechanisms of own needs of power plants and research results are reliable definitely enhance the efficiency of their operation. However, a material described in the literature reviewed obvious that its use in the practice of specific operating units of own needs power plants needed substantial revision of it. Because these sources are contained in the material presented in the general conceptual form, which makes it difficult to use on specific situations with different motor types for different purposes and capacities, and features of power circuits.

In this context, it is evident that today not enough attention highlighted the issues of development of means of analyzing modes of electric motors of own needs the PP, which would be suitable for direct use in their practice use. Clearly, more reliable results concerning modes of electric motors $\mathrm{ON}$ can be based on the solution of differential equations that describe processes in dynamic mode (start-up, run-down, self, and so on) with modern computer systems. In addition, analysis of the situation in question operation of power plants indicates that, on the one hand, the practice of service personnel mostly uses only normative materials and documents, and therefore cannot always get into the essence of regularities of electromagnetic and electromechanical processes EM specific units in their various modes of the particular circumstances and, on the other hand, to physical experiment in terms of the analysis of modes of electric motors of $\mathrm{ON}$ in terms of the energy operation of power block not only difficult but often impossible.

The above gives reason to believe that the development of tools to analyze modes of electric motors own needs TPP, which serve as mathematical models and corresponding software systems is an actual scientific and practical problems.

The goals of investigations. Improving the reliability and efficiency of thermal power plants is only possible through the maximum utilization of knowledge in the context regularities of flow of electromagnetic and electromechanical processes that occur primarily in the turbo generators and electric motors in the systems mechanisms to their needs during their operation in normal and emergency modes of to the specific terms and condition these motors (connection schemes and the specific situation of the system $\mathrm{ON}$ power in the relationship of its elements IL themselves). The research results obtained in the literature (including listed here) allow only general and predominantly qualitative estimate modes EM. Combining advanced theories of mathematical modeling in the field of electricity and electrical engineers with the capabilities of modern information technology will make it possible to develop a mathematical model of a high level of adequacy, based on which, in turn, create a corresponding set of programs with which you can quickly perform calculations necessary operating modes and operational decisions concerning the positive effects on the motor.

Thus, the goal of the paper is to develop a mathematical model of the two short-induction motors smoke exhausters unit of thermal power stations that are powered by the transformer's own needs, and appropriate software designed for the rapid analysis of motor operating modes using modern computer technology.

Presentation of main material. In the real world of individual thermal power boiler smoke one driven by two short-circuited electric motor. To achieve adequacy of mathematical modeling of motor of smoke exhausters sufficient for practical purposes it is necessary to model processes not only the motors themselves, but also in the transformer of own needs (TON) unit, which feed motors. This will allow better display motor operating conditions and will enable modeling processes that occur in motors during the loss and recovery of working power TON and associated with this mode of self induction motors.

Based on these considerations, with the object of study made electrical complex circuit diagram is shown in Fig. 1. 


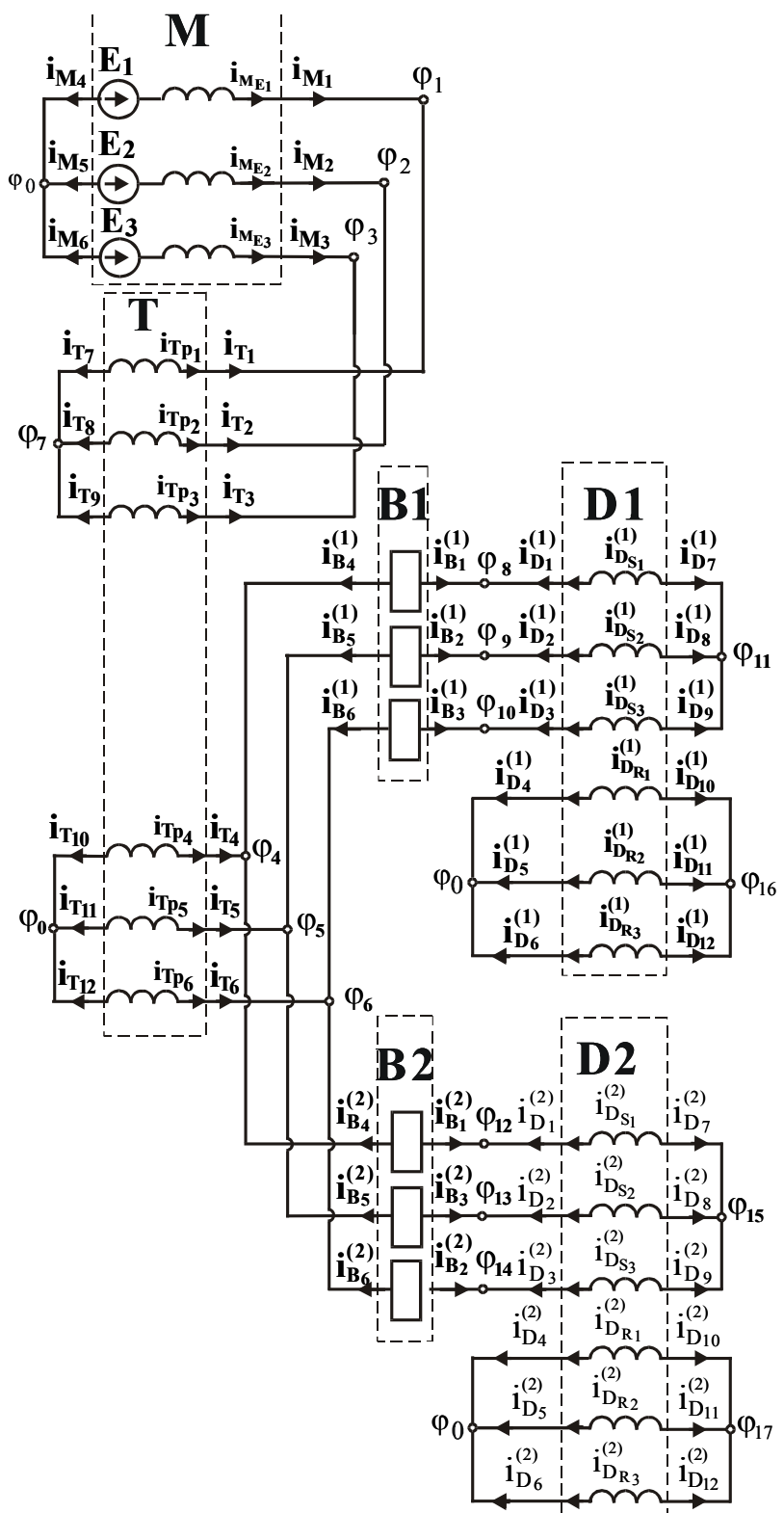

Fig. 1. Electrical circuit diagram of the complex «electric network - transformer - two induction motors»

This Figure shows that smoke exhausters electric motors powered by a transformer secondary winding their needs through switches, and the primary winding of the transformer is powered from the mains, which are presented turbine. In Fig. $1 M$ letter marked three-phase electric network; TON letter marked $T$; texts $B 1, B 2-$ switches that connect through the stator winding induction motor to the secondary winding TON and inscriptions $D 1, D 2$ - two induction motors of the smoke exhausters. The letters indicated potentials $\varphi$ independent nodes schemes, the letter «i $\rangle$ - current phase of structural element branches, and the letter $E$ - electromotive force network. In the lower index numbers marked numbers of independent units, the numbers of branches structural phase circuit elements and external room-branch structural elements. The letter $M, T$ indicated in subscript currents belonging to external branches and network transformer, and inscriptions $M_{\mathrm{E}}$ and $T_{\mathrm{P}}$ - belonging to the internal network and current transformer. The letters $S, R$ indicated in subscript currents belonging to the stator and rotor induction motor and the letter $D$ - external branches to the current induction motors.

Mathematical models of electrotechnical complex (ETC) «three-phase electric network - transformer - two induction motors» (EN $-\mathrm{T}-\mathrm{IM})$ develop on the basis of the theory of mathematical modeling of electric machines, valve systems [6] and a number of other developments outlined in $[2,8]$. Thus, the mathematical model of the $\mathrm{ETC}$ «EN $-\mathrm{T}-\mathrm{IM} »$ is a system of differential equations for the state electrical circuit in Fig. 1 and differential equations mechanical condition for induction motors and smoke exhausters. The first set of equations describing electromagnetic processes of the entire circuit in Fig. 1, and the second - electromechanical processes that occur in asynchronous motors. The system of equations written in state electric phase coordinates and focuses on explicit numerical integration methods. Each of the structural elements (electrical network, transformer and switch, asynchronous motors) are in the form of equations multipoles recorded the second law of Kirchhoff. Consider the mathematical models of structural elements.

Mathematical model of the first induction motor is designed according to [2, 6, 8]. Electromagnetic and electromechanical processes describe the electrical system of differential equations balance and mechanical balance differential equation respectively. The first group form equations based on Kirchhoff's laws, and describe the mechanical balance d'Alembert equation.

So, will be the first electric induction motor vector equations describe the external branches which is as follows [6]:

$$
p i_{D}^{(1)}+\Gamma_{D}^{(1)} \cdot \varphi_{D}^{(1)}+C_{D}^{(1)}=0,
$$

where $p=d / d t$ is the differential operator in time $t$;

$i_{D}^{(1)}=\left(i_{D_{1}}^{(1)}, i_{D_{2}}^{(1)}, i_{D_{3}}^{(1)}, i_{D_{4}}^{(1)}, i_{D_{5}}^{(1)}, i_{D_{6}}^{(1)}, i_{D_{7}}^{(1)}, i_{D_{8}}^{(1)}, i_{D_{9}}^{(1)}, i_{D_{10}}^{(1)}, i_{D_{11}}^{(1)}, i_{D_{12}}^{(1)}\right)$

is the vector of external branches currents;

$\varphi_{D}^{(1)}=\left(\varphi_{D_{1}}^{(1)}, \varphi_{D_{2}}^{(1)}, \varphi_{D_{3}}^{(1)}, \varphi_{D_{4}}^{(1)}, \varphi_{D_{5}}^{(1)}, \varphi_{D_{6}}^{(1)}, \varphi_{D_{7}}^{(1)}, \varphi_{D_{8}}^{(1)}, \varphi_{D_{9}}^{(1)}, \varphi_{D_{10}}^{(1)}, \varphi_{D_{11}}^{(1)}, \varphi_{D_{12}}^{(1)}\right)$ is the vector of external nodes potentials;

$$
\Gamma_{D}^{(1)}=\left[\begin{array}{cc}
\left(L_{D}^{(1)}\right)^{-1} & -\left(L_{D}^{(1)}\right)^{-1} \\
-\left(L_{D}^{(1)}\right)^{-1} & \left(L_{D}^{(1)}\right)^{-1}
\end{array}\right] ; C_{D}^{(1)}=\left[\begin{array}{c}
\left(L_{D}^{(1)}\right)^{-1} \\
-\left(L_{D}^{(1)}\right)^{-1}
\end{array}\right] \times E_{D}^{(1)}
$$

are the matrix of coefficients and the vector of free members.

Components of the matrix of coefficients have the following structure:

$$
L_{D}^{(1)}=\left[\begin{array}{ll}
L_{S, S}^{(1)} & L_{S, R}^{(1)} \\
L_{R, S}^{(1)} & L_{R, R}^{(1)}
\end{array}\right],
$$

where $L_{S, S}^{(1)}$ is the matrix of own inductances of stator circuits; $L_{S, R}^{(1)}, L_{R, S}^{(1)}$ are the matrices of mutual inductances between stator and rotor circuits and between rotor and stator circuits, respectively; $L_{R, R}^{(1)}-$ is the matrix of own inductances of rotor circuits.

Components of the vector of free members have the following structure in (2) $E_{D}^{(1)}=L_{D S, R}^{(1)} \cdot i_{D_{R}}^{(1)}+R_{D S}^{(1)} \cdot i_{D_{S}}^{(1)}$, where $L_{D_{S, R}}^{\prime(1)}$ is the derivative of the matrix $L_{D S, R}^{(1)}$ by the rotation angle of the motor $\gamma_{D}^{(1)}$; 
$R_{D_{S}}^{(1)}=\operatorname{diag}\left(R_{D_{S_{1}}}^{(1)}, R_{D_{S_{2}}}^{(1)}, R_{D_{S_{3}}}^{(1)}\right)$ is the diagonal matrix of the stator phase active resistances; $i_{D_{S}}^{(1)}=\left(i_{D_{S_{1}}}^{(1)}, i_{D_{S_{2}}}^{(1)}, i_{D_{S_{3}}}^{(1)}\right)=\left(i_{D_{1}}^{(1)}, i_{D_{2}}^{(1)}, i_{D_{3}}^{(1)}\right)$; $i_{D_{R}}^{(1)}=\left(i_{D_{R_{1}}}^{(1)}, i_{D_{R_{2}}}^{(1)}, i_{D_{R_{3}}}^{(1)}\right)=\left(i_{D_{4}}^{(1)}, i_{D_{5}}^{(1)}, i_{D_{6}}^{(1)}\right)$ are the vectors of phase currents of the stator and rotor, respectively.

Mechanical processes that occur in induction motor differential describe the equation of mechanical equilibrium. For the first induction motor this equation is as follows:

$$
\left(J_{D}^{(1)}+J_{H}^{(1)}\right) \cdot p \omega_{D}^{(1)}-\left(M_{D}^{(1)}-M_{H}^{(1)}\right)=0,
$$

where $J_{D}^{(1)}, J_{H}^{(1)}$ are the moment of inertia of the motor rotor and rotating parts of its mechanical load, respectively; $p \omega_{D}^{(1)}$ is the derivative of the rotor rotation speed by time; $M_{D}^{(1)}$ is the motor electromagnetic torque; $M_{H}^{(1)}$ is the mechanical load torque on the motor shaft. formula:

Mechanical load torque is determined by the

$$
M_{H}^{(1)}=M_{H_{0}}^{(1)}+K_{H_{1}}^{(1)} \cdot\left(\omega_{H}^{(1)}\right)^{K_{H 2}^{(1)}},
$$

where $M_{H_{0}}^{(1)}$ is the static mechanical load torque; $K_{H_{1}}^{(1)}$ is the ratio factor; $K_{\mathrm{H}_{2}}^{(1)}$ is the exponent of the rotation speed $\omega_{H}^{(1)}$.

The structure of the formula (5) allows the selection of numerical values of its individual elements as input to make choices required mechanical characteristics of motor load among a number of possible.

Electrical circuit breakers envision separate systems of three-phase branches Fig. 1. The mathematical models of switches each of the phases present electrical branch consisting of series-connected active resistance and inductance values for which the on state of the switch are made small (e.g., corresponding to real value) and for open-loop-large, i.e. those that correspond disconnected circle in which no current. The transition from open-loop switch to a running state performed immediately (jump) and transition from a running state to off - a smooth increase in resistance and inductance phase branch circuit breaker during certain specified time (corresponding realtime switching) for objectified law as a function of time. It provides lines of second law of increasing resistance and inductance phase branch circuit breaker. This approach will help to reduce the current switch to a certain value, which is at the start off of the switch to zero.

So, electrical state of the first switch is described by the vector equation of external branches in the form:

$$
p i_{B}^{(1)}+\Gamma_{B}^{(1)} \cdot \varphi_{B}^{(1)}+C_{D}^{(1)}=0
$$

where $i_{B}^{(1)}=\left(i_{B_{1}}^{(1)}, i_{B_{2}}^{(1)}, i_{B 3}^{(1)}, i_{B 4}^{(1)}, i_{B 5}^{(1)}, i_{B_{6}}^{(1)}\right)$ is the vector of external branches currents;

$\varphi_{B}^{(1)}=\left(\varphi_{B 1}^{(1)}, \varphi_{B 2}^{(1)}, \varphi_{B 3}^{(1)}, \varphi_{B 4}^{(1)}, \varphi_{B 5}^{(1)}, \varphi_{B 6}^{(1)}\right)$ is the vector of external branches potentials;

$$
\Gamma_{B}^{(1)}=\left[\begin{array}{cc}
\left(L_{B}^{(1)}\right)^{-1} & -\left(L_{B}^{(1)}\right)^{-1} \\
-\left(L_{B}^{(1)}\right)^{-1} & \left(L_{B}^{(1)}\right)^{-1}
\end{array}\right] ; C_{B}^{(1)}=\left[\begin{array}{c}
\left(L_{B}^{(1)}\right)^{-1} \\
-\left(L_{B}^{(1)}\right)^{-1}
\end{array}\right] \times E_{B}^{(1)}
$$

are the matrix of coefficients and the vector of free members in which $L_{B}^{(1)}=\operatorname{diag}\left(L_{B_{1}}^{(1)}, L_{B_{2}}^{(1)}, L_{B_{3}}^{(1)}\right)$ is the diagonal matrix of inductances, $E_{B}^{(1)}=\operatorname{colon}\left(R_{B_{1}}^{(1)} \cdot i_{B_{1}}^{(1)}, R_{B_{2}}^{(1)} \cdot i_{B_{2}}^{(1)}, R_{B_{3}}^{(1)} \cdot i_{B_{3}}^{(1)}\right) \quad$ is the column vector of voltage drop on switch phase supports.

The mathematical model of the transformer of own needs is represented in the correspondence with $[6,8]$ by the differential equation of external branches in the form:

$$
p_{i T}+\Gamma_{T} \cdot \varphi_{T}+C_{T}=0
$$

where $i_{T}=\left(i_{T_{1}}, i_{T_{2}}, i_{T_{3}}, i_{T_{4}}, i_{T_{5}}, i_{T_{6}}, i_{T_{7}}, i_{T_{8}}, i_{T_{9}}, i_{T_{10}}, i_{T_{11}}, i_{T_{12}}\right)$ is the vector of external branches currents; $\varphi_{T}=\left(\varphi_{T_{1}}, \varphi_{T_{2}}, \varphi_{T_{3}}, \varphi_{T_{4}}, \varphi_{T_{5}}, \varphi_{T_{6}}, \varphi_{T_{7}}, \varphi_{T_{8}}, \varphi_{T_{9}}, \varphi_{T_{10}}, \varphi_{T_{11}}, \varphi i_{T_{12}}\right)$ is the vector of external nodes potentials;

$$
\Gamma_{T}=\left[\begin{array}{cc}
\left(L_{T}\right)^{-1} & -\left(L_{T}\right)^{-1} \\
-\left(L_{T}\right)^{-1} & \left(L_{T}\right)^{-1}
\end{array}\right] ; C_{T}=\left[\begin{array}{c}
\left(L_{T}\right)^{-1} \\
-\left(L_{T}\right)^{-1}
\end{array}\right] \times E_{T}
$$

is the matrix of coefficients and the vector of free members in which $L_{T}$ is the matrix of inductances with dimension of $6 \times 6$;

$$
\begin{aligned}
& E_{T}=\left(R_{T p_{1}} \cdot i_{T p_{1}}, R_{T p_{2}} \cdot i_{T p_{2}}, R_{T p_{3}} \cdot i_{T p_{3}},\right. \\
& \left.R_{T p_{4}} \cdot i_{T p_{4}}, R_{T p_{5}} \cdot i_{T p_{5}}, R_{T p_{6}} \cdot i_{T p_{6}}\right)
\end{aligned}
$$

is the column vector of voltage drop on transformer phase branches supports.

Electrical networks present system of three-phase branches, each of which consists of series-connected active resistance, inductance and electric motive power AC. Phase electromotive forces shifted by 120 degrees. Equation of external branches of a three-phase electrical network is presented as follows:

$$
p i_{M}+\Gamma_{M} \cdot \varphi_{M}+C_{M}=0
$$

where $i_{M}=\left(i_{M_{1}}, i_{M_{2}}, i_{M_{3}}, i_{M_{4}}, i_{M_{5}}, i_{M_{6}}\right)$ is the vector of external branches currents;

$\varphi_{M}=\left(\varphi_{M_{1}}, \varphi_{M_{2}}, \varphi_{M_{3}}, \varphi_{M_{4}}, \varphi_{M_{5}}, \varphi_{M_{6}}\right)$ is the vector of external nodes potentials;

$$
\Gamma_{M}=\left[\begin{array}{cc}
\left(L_{M}\right)^{-1} & -\left(L_{M}\right)^{-1} \\
-\left(L_{M}\right)^{-1} & \left(L_{M}\right)^{-1}
\end{array}\right] ; C_{M}=\left[\begin{array}{c}
\left(L_{M}\right)^{-1} \\
-\left(L_{M}\right)^{-1}
\end{array}\right] \times E_{M}
$$

is the matrix of coefficients and the vector of free members in which

$L_{M}=\operatorname{diag}\left(L_{M_{1}}, L_{M_{2}}, L_{M_{3}}\right)$ is the diagonal matrix of inductances;

$E_{M}=\left(R_{M_{1}} \cdot i_{M_{1}}-e_{M_{1}}, R_{M_{2}} \cdot i_{M_{2}}-e_{M_{2}}, R_{M_{3}} \cdot i_{M_{3}}-e_{M_{3}}\right)$

is the column vector of free members, and $e_{M_{j}}=E_{m} \sin (\omega \cdot t-(j-1) \cdot \rho)(j=1,2,3)$, where $E_{m}$ is the amplitude of the network electromotive force; $\rho=2 \cdot \pi / 3$.

Mathematical models of the second induction motor and the second switch models are identical to the first motor and the first switch respectively.

The complete system of equations of electrical state is written in electric potential basis of independent nodes circuit in Fig. 1 and according to [6] is as follows:

$$
A \cdot \varphi+B=0 \text {, }
$$

Where $A, B$ are the matrix of coefficients and the vector 
of free members; $\varphi=\left(\varphi_{1}, \varphi_{2}, \ldots, \varphi_{17}\right)$ is the vector of independent nodes potentials in the circuit of Fig. 1.

Matrix coefficients and vector of the system of equations (12) formed from the matrix coefficients vector of (2) (7) (9) (10) and matrix of incidention structural elements of the circuit in Fig. 1 according to [6] by the formulas:

$$
\begin{gathered}
A=\Pi_{M} \cdot \Gamma_{M} \cdot \Pi_{M}^{t}+\Pi_{T} \cdot \Gamma_{T} \cdot \Pi_{T}^{t}+ \\
+\Pi_{B}^{(1)} \cdot \Gamma_{B}^{(1)} \cdot \Pi_{B}^{t(1)}+\Pi_{B}^{(2)} \cdot \Gamma_{B}^{(2)} \cdot \Pi_{B}^{t(2)}+ \\
+\Pi_{D}^{(1)} \cdot \Gamma_{D}^{(1)} \cdot \Pi_{D}^{t(1)}+\Pi_{D}^{(2)} \cdot \Gamma_{D}^{(2)} \cdot \Pi_{D}^{t(2)} ; \\
\quad B=\Pi_{M} \cdot C_{M}+\Pi_{T} \cdot C_{T}+ \\
+\Pi_{B}^{(1)} \cdot C_{B}^{(1)}+\Pi_{B}^{(2)} \cdot C_{B}^{(2)}+\Pi_{D}^{(1)} \cdot C_{D}^{(1)}+\Pi_{D}^{(2)} \cdot C_{D}^{(2)},
\end{gathered}
$$

where

$$
\begin{aligned}
& \Gamma_{M}, \Gamma_{T}, \Gamma_{B}^{(1)}, \Gamma_{B}^{(2)}, \Gamma_{D}^{(1)}, \Gamma_{D}^{(2)} ; \\
& C_{M}, C_{T}, C_{B}^{(1)}, C_{B}^{(2)}, C_{D}^{(1)}, C_{D}^{(2)}
\end{aligned}
$$

are the matrices of coefficients and vectors of free members of the electrical network, transformer, switches and induction motors;

$$
\Pi_{M}, \Pi_{T}, \Pi_{B}^{(1)}, \Pi_{B}^{(2)}, \Pi_{D}^{(1)}, \Pi_{D}^{(2)}
$$

are the matrices of incidention of the electrical network,transformer, switches and induction motors describing topology of the electrical circuit of Fig. 1, and

$$
\Pi_{M}^{\mathrm{t}}, \prod_{T}^{\mathrm{t}}, \Pi_{B}^{t(1)}, \Pi_{B}^{t(2)}, \Pi_{D}^{t(1)}, \Pi_{D}^{t(2)}
$$

are the matrices transpose regarding the incidention matrices (15).

Algorithm for calculating electromagnetic and electromechanical processes. The main inputs serve Catalog parameters: transformer own needs, smoke exhausters induction motors and electrical network and initial conditions systematized in integrated vector variables has the following structure:

$$
\begin{gathered}
V=\left(V_{M}, V_{T}, V_{B}^{(1)}, V_{B}^{(2)}, V_{D}^{(1)}, V_{D}^{(2)}, t\right)= \\
=\left(i_{M_{E 1}}, i_{M_{E_{2}}}, i_{M_{E_{3}}}, i_{T_{p_{1}}}, i_{T_{p_{2}}}, i_{T_{p_{3}}}, i_{T_{p_{4}}}, i_{T_{p_{5}}}, i_{T_{p_{6}}},\right. \\
i_{B_{1}}^{(1)}, i_{B_{2}}^{(1)}, i_{B_{3}}^{(1)}, i_{B_{1}}^{(2)}, i_{B_{2}}^{(2)}, i_{B_{3}}^{(2)}, \\
i_{D_{S_{1}}}^{(1)}, i_{D_{S_{2}}}^{(1)}, i_{D_{S_{3}}}^{(1)}, i_{D_{R_{1}}}^{(1)}, i_{D_{R_{2}}}^{(1)}, i_{D_{R_{3}}}^{(1)}, \gamma_{D}^{(1)}, \omega_{D}^{(1)}, \\
\left.i_{D_{S_{1}}}^{(2)}, i_{D_{S_{2}}}^{(2)}, i_{D_{S_{3}}}^{(2)}, i_{D_{R_{1}}}^{(2)}, i_{D_{R_{2}}}^{(2)}, i_{D_{R_{3}}}^{(2)}, \gamma_{D}^{(2)}, \omega_{D}^{(2)}, t\right) .
\end{gathered}
$$

Main stages of the processes calculation algorithm are:

- based on the initial conditions vector $V$ (16) and catalog data, forming the matrix coefficients and vector of structural elements and through them the coefficient matrix $A$ and the vector of the electric system of equations in the state (12), which solved regarding vector $\varphi$;

- to reverse course under the vector $\varphi$, define the vector $p V$ integration, which is the original integrated vector variable $\mathrm{V}(16)$ in time $t(p V=d V / d t)$;

- by one explicit numerical integration methods, based on the vector $p V$ integration and integration step $\Delta t$, defining new value vector $V$;

- described the procedure continues to exit the current integration time $t$ out of the final.
Based on the above-described mathematical models and algorithms developed software system programming language FORTRAN, which allows using computers to calculate electromagnetic and electromechanical processes in electrotechnical complex systems, smoke exhausters TPP.

Below is a generalized analysis of modes of asynchronous motors smoke exhausters thermal power on the basis of the results obtained by mathematical modeling.

In practice, the operation modes of asynchronous motors of smoke exhausters defined mode of operation of thermal power. Depending on the amount of power delivery to the grid must reconcile the boiler unit of power, and hence smoke exhausters work. This means that motors should provide a balanced performance smoke exhausters, defined modes including their motors periodically unlocking. Accordingly, a practical interest is in motors of smoke exhauster mode, which provides switching and unlocking individual motors that provide information on starting mode and free wheel mode. In addition, it is important to model treatment short voltage loss at transformer captive switching to backup power motors and further self-start.

Thus, the simulation of electromagnetic and electromechanical processes to fulfill this mode of induction motors smoke exhausters: at the beginning (at time $t_{1}=0 \mathrm{~s}$ ) performed simultaneous launch of both IM. At time $t_{2}=5 \mathrm{~s}$ stops supply voltage to the transformer in ON cont interval $\Delta t=0.2 \mathrm{~s}$. At time $t_{3}=7 \mathrm{~s}$ denies first motor, and at time $t_{4}=20 \mathrm{~s}$ it on again. At time $t_{5}=26 \mathrm{~s}$ off both induction motors. This mode will allow smoke exhausters motor cover almost all the important stages of their work, including the group ran and simultaneously assess the possibilities offered by mathematical models and corresponding software system.

Perform calculation of electromagnetic and electromechanical processes motors of smoke exhausters of the 11-th unit of the Burshtyn TPP. The power of these motors of $1500 \mathrm{~kW}$ and $850 \mathrm{~kW}$ respectively and the number of poles is 8 and 10 .

Input data catalog data serve as induction motors, transformers and electricity needs of their network and initial conditions, which serves as the integrated vector variables (16). In addition to the input data includes information complementary nature that defines modes of the software complex (integration step, the final integration time, and so on).

Simulation results serve as calculated according to the time of instantaneous values of potential independent units, transformer phase currents, phase currents of the stator and rotor rotation speed motors and electromagnetic motor torque and mechanical resistance points smoke exhausters.

Fig. 2 shows calculated depending on the instantaneous values of phase currents of the stator of the first motor. Waveform phase stator currents reflect the entire operating cycle of the motor (intervals of work and stop) and the nature of the starting transients. Fig. 3 shows a calculated depending on the instantaneous values of phase currents of the first rotor motor, which in addition to the stator currents complementary information 
about the peculiarities of electromagnetic processes first induction motor in quality and proportion. Curves rotor currents are so important that it happens in the rotor electromagnetic energy conversion.

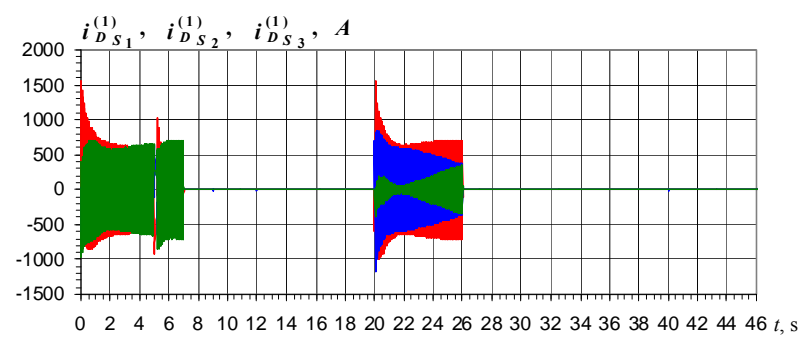

Fig. 2. $i_{D_{S_{1}}}^{(1)}, i_{D_{S_{2}}}^{(1)}, i_{D_{S_{3}}}^{(1)}-$ phase currents of the stator winding D1

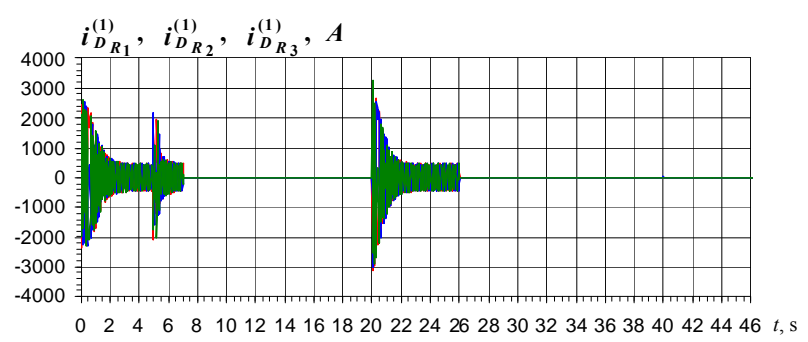

Fig. 3. $i_{D_{R 1}}^{(1)}, i_{D_{R 2}}^{(1)}, i_{D_{R 3}}^{(1)}-$ phase currents of the rotor winding D1

Fig. 4 and 5 respectively depict calculated depending on the instantaneous values of phase currents stator and rotor of the second motor. The curves of the currents clearly reflect the mutual influence of asynchronous motors on each other. And this influence is manifested through the change of variables one motor current depending on the second (when the power on). From Fig. 4 and 5 it can be seen that the current second motor when the first big off.

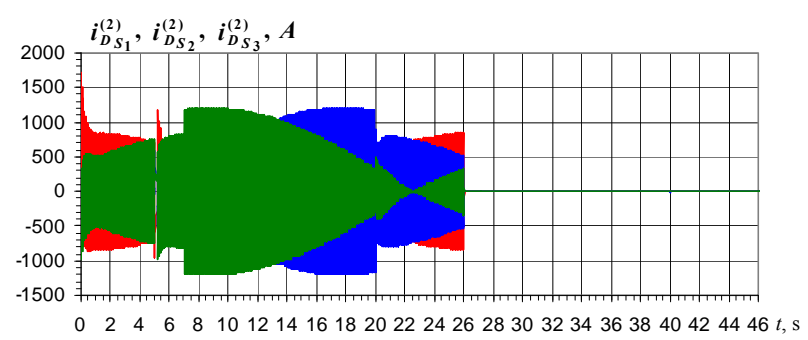

Fig. 4. $i_{D_{S_{1}}}^{(2)}, i_{D_{S_{2}}}^{(2)}, i_{D_{S_{3}}}^{(2)}$ - phase currents of the stator winding D2

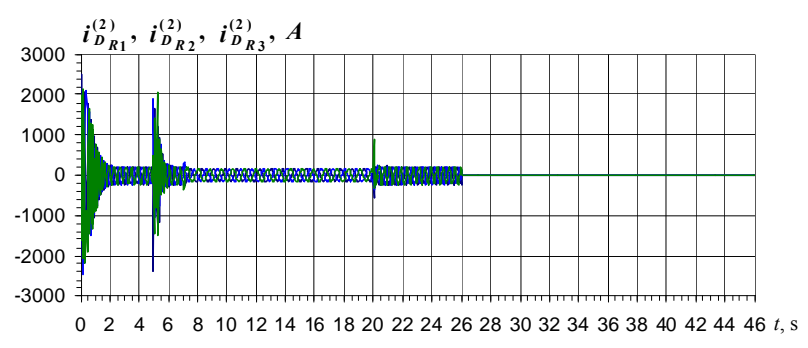

Fig. 5. $i_{D_{R_{1}}}^{(2)}, i_{D_{R_{2}}}^{(2)}, i_{D_{R_{3}}}^{(2)}$ - phase currents of the rotor winding D2

Shown in Fig. 2-5 depending characterize current patterns of electromagnetic processes. But to assess the operation ability of motors of smoke exhausters must have accurate information about the regularities of electromechanical processes. Such information serve as calculated depending on the electromagnetic motor torque and mechanical resistance smoke exhausters points, which for the first and second motors respectively shown in Fig. 6, 7.

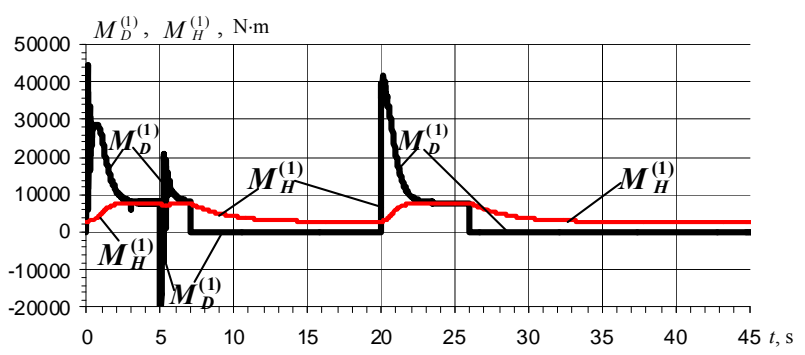

Fig. 6. $M_{D}^{(1)}, M_{H}^{(1)}$ - electromagnetic torque of the first motor and mechanical moment of resistance of its smoke exhauster

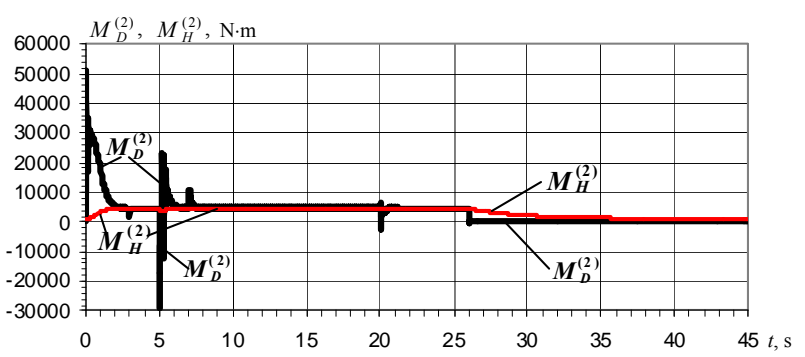

Fig. 7. $M_{D}^{(2)}, M_{H}^{(2)}$ - electromagnetic torque of the second motor and mechanical moment of resistance of its smoke exhauster

From these Figures shows that the nature of the curve reflects electromagnetic moments regularities of electromagnetic processes asynchronous motors. At the initial stage of starting points transient electromagnetic motors are alternating in nature. This is a large (close to unity) the value of slip induction motors. As mentioned electromagnetic gain momentum out of the point zone of the sign changing and become more sustainable value and a steady constant.

To obtain correct results of asynchronous motors regarding important to have not only the functional dependence of the electromagnetic motor torque, but the curves point mechanisms are driven by motors. Mechanical resistance points and blowing smoke exhausters mechanisms for changing fan characteristic that is proportional to the square of speed. The value of static mechanical moment for these units is very small relative to the mechanical moment in nominal mode and is friction torque. Defaults mechanical moment curves smoke exhausters fans get the point balancing points in electromagnetic motors electrical resistance with mechanical fan moments that clearly illustrate the curves in Fig. 6, 7.

Performance smoke exhausters determined by the frequency of their rotation. Therefore, in terms of motor operating practices smoke exhausters units of thermal power plants is an important law change rotor speed induction motors.

Rotor speed induction motors frequency determined by the supply voltage and the number of pole pairs. But, on the other hand, the rotor speed IM affects value since the mechanical load. Therefore, the motor speed is 
determined by the resulting smoke exhausters influence of these two factors. Fig. 8 shows the calculated depending on the time rotor speed (in radians per second) of two induction motors $\omega_{D}^{(1)}=\omega_{D}^{(1)}(t)$ - the first and $\omega_{D}^{(2)}=\omega_{D}^{(2)}(t)-$ the second.

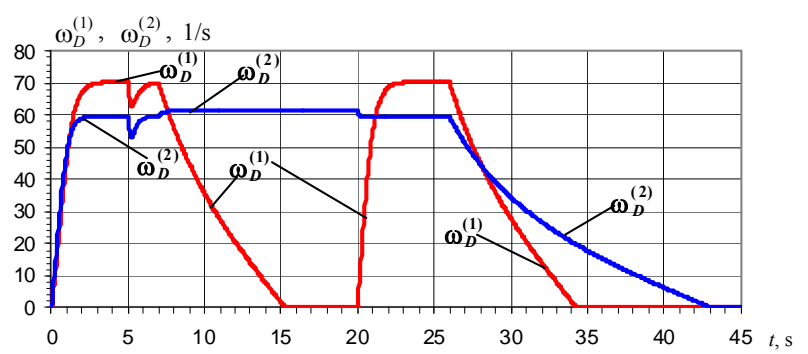

Fig. 8. $\omega_{D}^{(1)}, \omega_{D}^{(2)}-$ mechanical rotation speed of the induction motors rotors

The nature of the curves in Fig. 8 gives a fairly complete and integrated picture of the substantive operation of units smoke exhausters in general, as well as during motor starting mode and during their run-down modes, in particular. After all, they reflect the performance of the smoke exhausters not only in these modes, but the mutual influence their work and display their work during power loss TON. Mutual influence is manifested in increasing motor rotational speed of the second motor on the period of time when the first motor off (time from $t=7 \mathrm{~s}$ to $t=20 \mathrm{~s}$, see curves in Fig. 9). Nature of Fig. 9 allows to determine the run-time motor that depends on the mass moment of inertia wing characteristics and mechanical load.

Smoke units are responsible to their own needs, because electric motors smoke exhausters included in the list of those subject to self. Therefore, for practical operation is important to have accurate information about the regularities of electromagnetic and electromechanical processes during self-run. As noted above, in our experiment provides self-fulfillment after the break power equal to $0.2 \mathrm{~s}$. In this situation it is important to have functional versus time rpm and outlines current motors. The nature of motor speed curves during self motors are illustrated in Fig. 8, which is easy to determine the depth of the failure to coordinate interval voltage loss and recovery time nominal motor speed after the twice supply voltage.

For further information regarding the self if you can analyze patterns of electromagnetic processes based on the analysis of functional dependencies instantaneous values of phase currents of the stator and rotor induction motors. Fig. 9, 10 show the calculated depending on the instantaneous values of phase currents of the first stator and rotor induction motor. From Fig. 9 shows that during the period of time pressure loss phase currents is aperiodic nature with a tendency to decrease their values, and after recovery voltage characteristic is availability aperiodic components that are smaller, than when starting the motor from rest. But seats rotor currents in the range of loss with sinusoidal voltage shape and their amplitude tends to decrease.

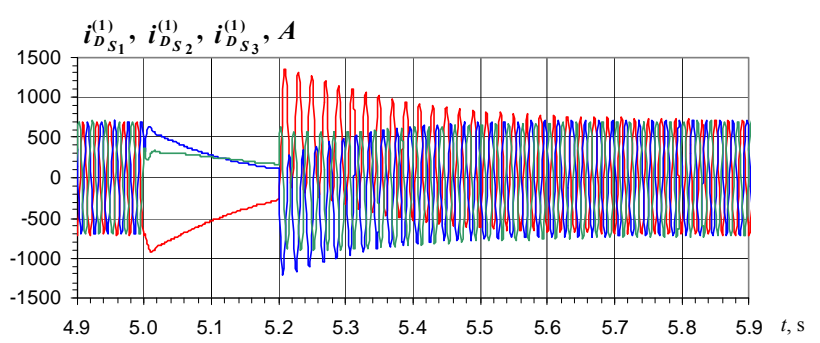

Fig. 9. $i_{D_{S_{1}}}^{(1)}, i_{D_{S_{2}}}^{(1)}, i_{D_{S_{3}}}^{(1)}$ - phase currents of the stator winding D1

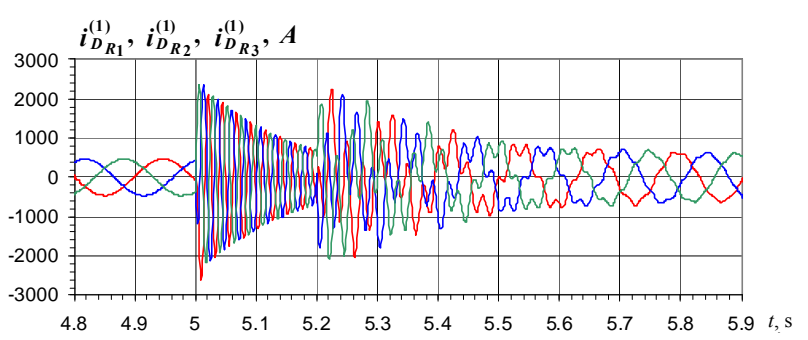

Fig. 10. $i_{D_{R 1}}^{(1)}, i_{D_{R 2}}^{(1)}, i_{D_{R 3}}^{(1)}-$ phase currents of the rotor winding D1

Fig. 11 and 12 shows the calculated depending on the instantaneous values of phase currents second stator and rotor induction motor.

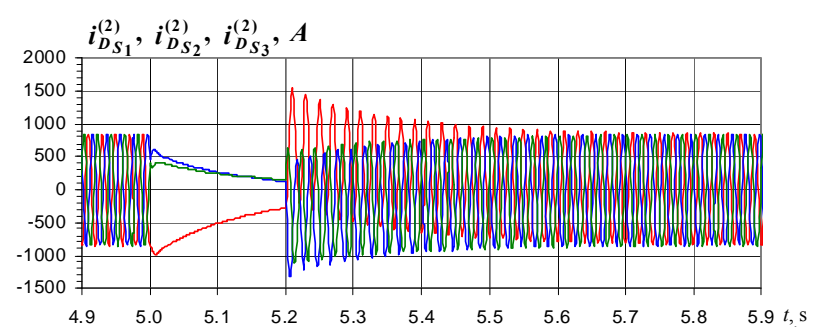

Fig. 11. $i_{D_{S_{1}}}^{(2)}, i_{D_{S_{2}}}^{(2)}, i_{D_{S_{3}}}^{(2)}-$ phase currents of the stator winding D2

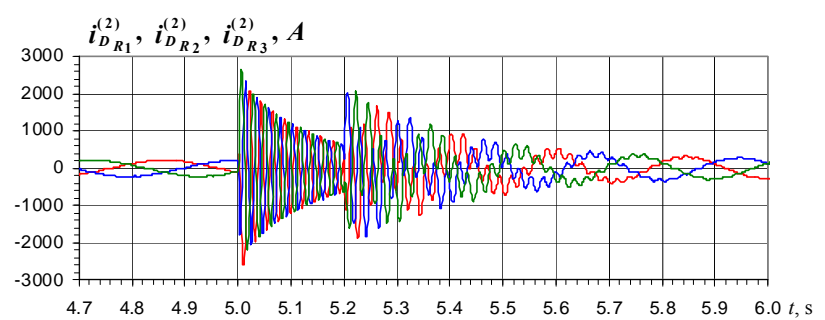

Fig. 12. $i_{D_{R 1}}^{(2)}, i_{D_{22}}^{(2)}, i_{D_{R 3}}^{(2)}$ - phase currents of the rotor winding D2

Such experiments had not observed, and therefore, in my opinion, they are the subject of scientific innovation. Results of mathematical experiments allow self-assess conditions for the possibility of its success, which is practical means-city.

Pattern of change of phase currents second motor are similar to the first, and thus analyze them separately is not necessary.

Conclusions.

1. Analysis of scientific literature shows that the present study modes of motor smoke exhausters TPP performed only in the context of general assemblies of own needs based on the main provisions of the classical theory of electrical machines without the use of differential equations to describe the dynamic modes of the motors, which significantly reduces opportunities reliable results. Therefore, development of special means 
of investigation modes of motors of smoke exhausters TPP as mathematical models as a system of differential equations electrical and mechanical condition of the motor smoke exhausters TPP and the corresponding software system is an actual scientific and practical problem.

2. The mathematical model of induction motors smoke exhausters that addresses the key factors influencing the course of electromagnetic and electromechanical processes, communications circuits nonlinearity electromagnetic motors, motors and mutual influence transformer's own needs, the impact of the loss and recovery of supply voltage, and mutual the impact of the motor and mechanism driven by a motor.

3. On the basis of a mathematical model developed software system that enables the TPP in operation to carry out research almost essential modes of the system of induction motors smoke exhausters. Mathematical model and software system lets you simulate electromagnetic and electromechanical processes in symmetric and asymmetric, steady-state and dynamic modes.

4. Using the developed software system performed research of electromagnetic and electromechanical processes asynchronous motors smoke exhausters TPP major modes. In particular, studies starting mode, after the loss of self-renewal and voltage, and received qualitative and quantitative parameters freewheel motors.

\section{REFERENCES}

1. Abbasov E.M., Golodnov Iu.M., Zil'berman V.A., Murzakov A.G. Sobstvennye nuzhdy teplovykh elektrostantsii [Own needs of thermal power plants]. Moscow, Energoatomizdat Publ., 1991. 272 p. (Rus).

2. Vasyliv K.M. Metody $i$ modeli analizu protsesiv avtonomnykh system elektrozhyvlennya na bazi asynkhronizovanoho heneratora $z$ bezkontaktnym kaskadnym modul'ovanym zbudzhuvachem. Diss. dokt. techn. nauk
[Methods and models for analyzing the processes of autonomous power supply systems based on an asynchronous generator with a noncontact cascade modulated exciter. Doc. tech. sci. diss.]. Kyiv, 2010. 398 p. (Ukr).

3. Kurbangaliev U.K. Samozapusk dvigatelei sobstvennykh nuzhd elektrostantsii [Self-starting engines for power plants own needs]. Moscow, Energoizdat Publ., 1982. 56 p. (Rus).

4. Lahutin V.M., Teptya V.V., Vyshnevs'kyy S.Ya. Vlasni potreby elektrychnykh stantsiy [Own needs of power plants]. Vinnytsya, VNTU Publ., 2008. 102 p. (Ukr).

5. Neklepaev B.N. Elektricheskaia chast' elektrostantsii $i$ podstantsii [Electric part of power plants and substations]. Moscow, Energoatomizdat Publ., 1986. 640 p. (Rus).

6. Plakhtyna E.G. Matematicheskoe modelirovanie elektromashinno-ventil'nykh sistem [Mathematical modeling of electro-machine-valve systems]. Lviv, Vishcha shkola Publ., 1986. 164 p. (Rus).

7. Syromiatnikov I.A. Rezhimy raboty asinkhronnykh $i$ sinkhronnykh dvigatelei [Modes of operation of asynchronous and synchronous motors]. Moscow, Energoatomizdat Publ., 1984. 240 p. (Rus).

8. Fil'ts R.V. Matematicheskie osnovy teorii elektromekhanicheskikh preobrazovatelei [Mathematical foundations of the theory of electromechanical transducers]. Kyiv, Naukova dumka Publ., 1979. 208 p. (Rus).

9. Vasil'eva A.A. Elektricheskaia chast' stantsii i podstantsii [Electrical part of stations and substations]. Moscow, Energoatomizdat Publ., 1990. 576 p. (Rus).

Received 30.05.2017

K.M. Vasyliv, Doctor of Technical Science, Professor,

Lviv Polytechnic National University,

28a, S. Bandera Str., Lviv, 79013, Ukraine, phone +380322226403 ,

e-mail: karl.vasyliv@gmail.com

How to cite this article:

Vasyliv K.M. A mathematical model of thermal power plants smoke exhausters induction motors system operation modes. Electrical engineering \& electromechanics, 2017, no.3, pp. 19-26. doi: 10.20998/2074-272X.2017.3.03. 